\title{
Towards an integrated approach for reducing the conflict between elephants and people: a review of current research
}

\author{
Ferrel V. Osborn and Guy E. Parker
}

\begin{abstract}
Managers attempting to reduce crop damage by elephants encounter a range of complex technical and social issues. Subsistence farmers bear the costs associated with maintaining wild elephant populations and this can confound interventions designed to improve the livelihood security of farmers. We present a review of the issues that influence the success and failure of methods
\end{abstract}

used to reduce crop damage, and suggest that an integrated, community-based, low-tech approach will be the most sustainable solution to this conflict.

Keywords Africa, crop raiding, elephants, farmers, human-animal conflict.

\section{Introduction}

Conflict between elephants and local peoples is a major concern for wildlife management and rural development initiatives across Africa (Taylor, 1999; O'ConnellRodwell et al., 2000). This conflict typically involves crop damage by elephants, and solutions are generally set within a policy and legislative framework that attempts to address both wildlife management issues and rural development objectives. Many initiatives have been designed to address crop loss because this can undermine the success of other programmes related to agriculture or wild land conservation (Hoare, 1995). This issue can also threaten the viability of wild animal populations by creating a confrontational atmosphere between farmers and wildlife managers (Taylor, 1999). In some areas the problem is chronic, predictable and threatens the livelihood security of farmers living near wildlife (Hill, 1998). Rural communities can have an influential political voice, and crop raiding often becomes a flash point for a range of local issues such as settlement and access to resources (Barnes et al., 1995).

Crop damage affects subsistence farmers directly through loss of their primary food and cash resources, and indirectly though a variety of social costs. Rural people can express their frustration with unchecked crop loss through passive resistance to, or even sabotage of, development projects (Hill et al., 2000). Wildlife personnel who have the authority to manage elephants

Ferrel V. Osborn (Corresponding author) and Guy E. Parker Mid Zambezi Elephant Project, 37 Lewisam Ave, Chisipite, Harare, Zimbabwe.

E-mail: mzep@africaonline.co.zw

Received 8 February 2002. Revision requested 7 June 2002. Accepted 8 October 2002. are generally impeded by a lack of funds, trained personnel and equipment. Farmers often feel powerless to combat the problem, and hold wildlife managers responsible for crop losses and expect some form of compensation (AfESG, 2000). Years of piecemeal 'problem animal control' (PAC) activities have made little progress towards long-term solutions to these issues.

Most of the methods currently in use fail to resolve this conflict for logistical and management reasons that compound the difficulties of implementing PAC programmes in remote areas. In this paper we suggest a new approach to PAC that is focused on what communities are able and willing to do for themselves. Shifting the responsibility for crop protection to farmers and providing the tools they need to repel animals is, at least theoretically, an approach that is more sound than any single technical solution.

\section{Current methods to mitigate conflict}

The options for reducing conflict between elephants and people have been documented in numerous studies across Africa (Barnes, et al., 1995; Hoare, 1995; Wunder, 1996; Osborn, 1998) and fall into two general categories: passive and active. Passive systems attempt to limit the movement of 'target species' into areas of agriculture. Barriers such as thorn branches, wooden or stone fences, trenches and electric fencing are used in many countries. Active systems are typically utilized in fields at night, and include 'drive them away' defences used by farmers (e.g. chasing animals by banging on tins or drums, shouting and throwing objects), and in some areas shots are fired into the air to scare animals. The most common eventual solution is to kill one or more pest in order to deter other animals from returning and to compensate 
farmers with meat. This strategy has been shown to have no deterrent effect on the behaviour of elephants associated with the animal killed (Osborn, 1998). Hoare (2001) speculated that there is a 'problem component' in which regardless of how many problem elephants are removed others will replace them.

Conflict between elephants and people persists even where considerable resources have been devoted to solving the problem. This can be attributed to a range of factors, including technical faults, lack of commitment of the farmers and limited resources. One of the main causes of failure may be due to the centralized nature of 'reaction teams' and the logistics of patrolling lengthy boundaries between agriculture and elephant habitat. The ability to reduce crop-loss may also be due to the local conditions and the level of pressure from problem animals. Detailed analysis of each situation is needed to address specific causes of conflict, and this issue is being addressed by the Elephant Human Conflict Working Group (Hoare, 2000). There are, however, some commonalities between the successes and failures of different options that can be identified.

The success of passive systems depends on the material and design of a fence and the behaviour of the target species. Elephants, for example, eventually find a way to break through most fences, given enough time (Thouless, 1994). Barriers of stones or branches built by farmers are usually ineffective against elephants. Strong non-electrified fences have worked around Kruger National Park (I. Whyte, pers. comm.) but require regular maintenance. Electric fences have proven to be technically effective at limiting the movement of large mammals (Taylor, 1999) but the materials, installation and maintenance costs make this method impractical for large-scale applications in poorer developing countries. In addition, Thouless \& Sakwa (1995) concluded that elephants can overcome modifications to fences, implying that design, construction and voltage do not determine a fence's effectiveness. An expensive 'arms race' can develop between managers and elephants that are able to adapt quickly to new fence features designed to electrify the parts of the fence that elephants destroy.

It is unclear how effective many of the 'drive them away' defences are because little published information is available. References are occasionally made in unpublished management reports but, on the whole, the effectiveness of these methods has not been properly quantified, in part because of the difficulty of experimentation in a field situation. As elephant behaviour is relatively adaptable, animals may habituate over time to loud noises, fires, throwing of objects and shining of torches. Most active PAC methods tend to diminish in effectiveness after repeated use (Taylor, 1999). In some cases persistent bulls are not deterred by gunfire or the killing of one of the group (Osborn, 1998). The elephant responsible for the damage in the majority of cases cannot be identified and a token animal is killed merely to appease local people.

One of the main problems with all of these methods is that farmers do not regularly defend many of their fields during the night, when most raiding occurs. Farmers who sleep at their fields lose fewer crops because they can react when an animal approaches. For example, Lahm (1996) found that 36\% of farmers in Gabon whose crops were destroyed by elephants did nothing to deter them. Osborn (1998) found that 85\% of damage incidents occurred in undefended fields. Cooperation can be poor between farmers, and individuals are often left to defend their own fields. Developing a commitment on the part of farmers to patrol and defend their fields is difficult when they perceive this activity to be the responsibility of wildlife managers (MZEP, 2001).

Most interventions aimed at reducing crop-loss come from organizations outside of the affected community, which include government wildlife departments and external development organizations. Farmers expect the conflict to be resolved, and when it is not, often turn against the responsible agencies. Donor-funded technical solutions are often unsustainable because external agencies are reluctant to provide the high maintenance costs.

For example, fencing projects are usually implemented by international aid organizations. In many cases the ownership and responsibilities for the fence were not clarified by the organization to the farmers. These donor projects often fail over time because of deterioration of the fence and theft of valuable fence components. In many cases the erection of a fence cannot be justified economically because of the low return from the crops protected and the reoccurring investment needed from a donor. Rarely is a cost-benefit analysis undertaken, and if it is, the value of the lost crops is not found to justify the cost of the fence. Farmers see it as an outside intervention that they have no responsibility for, even if financed by money generated from wildlife in their area (Van der Wittenboren, 1999).

Every field site has specific characteristics and it is unlikely that any single method will work in all situations. The factors that affect this conflict can be influenced by geographical, social, cultural, historical, political and economic factors. In addition, the crucial issue of tangible benefits to farmers from living with wildlife are often ignored, or farmers are told that some abstract benefit will be forthcoming. We suggest that conflict persists in many wildlife rich areas because of a combination of four factors: namely, deficiencies in one-off technical solutions, lack of farmer vigilance and 
cooperation, habituation of animals to any one method, and the high human and social costs of living with wildlife.

\section{New approaches towards mitigation}

The resolution of this conflict will involve a range of modifications to the crops farmers select, the way they lay out their fields and their location in relation to movement patterns of crop raiding animals. The geography of each conflict situation must be examined to understand how pressure between farmers and elephants can be reduced. The 'hard edges' or boundaries of dense human settlement abutting a protected area tend to be areas of high conflict between wild animals and people. Numerous park planners have suggested the creation of buffer zones around protected areas, where human influence is graduated, thus relieving the pressure on both the protected area and the surrounding human population (Taylor, 1982). To create an effective buffer zone for elephants, a zone of 'reduced attractiveness' between the protected area and the surrounding crops must be created (Seidensticker, 1984; Thouless, 1994). This involves clearing secondary forest on the boundary and creating some distance between the boundary and cultivation. An optimal buffer zone should contain unpalatable crops grown adjacent to sub-optimal elephant habitat. Tests with buffer zones are being conducted in Zimbabwe, in which an area $5 \mathrm{~m}$ wide is cleared by farmers between the forest and fields (Osborn \& Parker, 2002). This has been found to increase the 'wariness' of elephants intent on raiding, and enabled farmers to see the elephants before they enter a field. String fences of two or three lines were added to the buffer zone if elephants crossed during previous nights and this increased the psychological barrier for crop raiding elephants.

The active management of a buffer zone with low-cost string fences, coupled with a vigorous deterrence regime, may instil recognition in elephants attempting to raid that the fence demarcates a 'no-go' area. Some success at limiting elephant movements with simple wire or string fences has been noted in Gabon (Languy, 1996), Ghana (M. Sam, pers. comm.), the Central African Republic (B. Curran, pers. comm.) and Zimbabwe (MZEP, 2001). While little conclusive data are available, it appears that in some situations simple, rudimentary, non-electrified fences can deter elephants. Fencing of any nature can prevent elephants from entering fields, at least in the short term. Low-tech fences made from locally available material erected by individual farmers may be more successful at reducing conflict than electric fences, and considerably less costly, because of the maintenance and theft issues associated with electric fencing.
The modification of PAC methods already in use by farmers may yield successful results. For example, improved access to materials for constructing PAC tools (e.g. string fences, sling shots, and bangers) coupled with addressing financial benefits that communities receive from wildlife. If the 'drive them away' defence does appear to meet with success in some situations, it is reasonable to assume that increased vigilance and cooperation combined with a wide array of different methods of deterrence would address the dual problems of lack of farmer participation and habituation by elephants.

Refining traditional methods of alarm (metal tins on strings) and scaring (drums and gunfire) may also work to reduce crop loss to elephants. For example, passive methods such as an alarm system using cow bells mounted on a string fence may be utilized that reduces the time a farmer must spend awake at night. To reduce time waiting for elephants, farmers can cooperate in a system of rotating 'guard duty' whereby only a few farmers patrol during the night, and when an elephant is sighted other farmers are woken to chase crop raiding elephants away (Osborn \& Parker, 2002). Active systems in which farmers are armed with whips and long poles on to which large bundles of dried grass are tied have also shown potential. The whips are cracked and the grass is set alight and a combination of the light and sound deter elephants from entering fields (C. Santipilli, pers. comm.). In Zambia, farmers report that whips are used to make a sound similar to a gunshot, and several individuals snapping these whips have kept elephants at bay for some time (Osborn \& Welford, 1997).

Some of the experimental work that has addressed the development of methods to keep elephants away from areas that humans occupy has included research on acoustic deterrents. Kangwana (1993) played recordings of Maasi cattle noise to elephants in Amboseli National Park, Kenya. These elephants are periodically hunted or injured by Maasi, and she concluded that elephants retreated from the recordings because of an association made between the danger posed by the Maasi, and the sounds of their cattle. A number of studies of elephant communication have demonstrated possibilities for manipulating elephants' behaviour using playback of vocalizations (Langbauer et al., 1991). Future initiatives could utilize certain calls that may be successful for repelling elephants. Whyte (1993) suggested that elephants may be emitting low frequency distress calls when they are being culled. If substantiated, these vocalizations could be useful for repelling elephants. The problem with using elephant vocalizations as a repellent, however, are that most are of low frequency and thus require expensive equipment to record and playback, and so far a noise that repels elephants has not been identified. 
O'Connell-Rodwell et al. (2000) found that tests conducted around waterholes in Namibia had no deterrent effects. However, advancements in technology and the reduction of the cost of these units may bring acoustic deterrents into wider application.

Tests with various chemical repellents have been undertaken in a number of field situations. In Malawi, Bell (1984) conducted trials with HATE 4C, a commercially available deer repellent, on fields and found no significant reduction in crop loss. In Zimbabwe, Osborn \& Rasmussen (1995) tested an aerosol made from Capsicum fruits and found it effective for repelling raiding elephants, but deployment was expensive. Chemical compounds with potential species-specific deterrent capabilities may prove an effective way to deter elephants. Gorman (1986) tested African elephant temporal gland secretion as an elephant repellent with ambiguous results. The avoidance reactions exhibited by female elephants to atomized secretions collected from the temporal glands of musth bulls (Perrin et al., 1996) are also potentially useful as a repellent for non-musth bulls. Recent tests with chemicals present in musth secretions, one ketone in particular, seems to prevent elephants from consuming food items encircled by rings of dilute concentrations of this naturally occurring substance (L.E.L. Rasmussen, pers. comm.). Finding technical solutions to the cost of production, and simplifying deployment mechanisms may facilitate the use of chemical repellents in the future.

\section{Discussion}

The central theme that emerges from examination of the failures of intervention is the need to decentralize responsibility for crop protection to the farmers. This represents a considerable shift in thinking, because farmers have historically depended on centralized PAC units to reduce this conflict. This shift may only be achieved if farmers are then presented with locally appropriate schemes that can provide a tangible reduction in crop loss. Crop raiding by elephants continues, despite the considerable amount of research and resources devoted to the problem over the last decade. The current methods to reduce conflict between elephants and farmers are either expensive or ineffective. If it is essential to bring farmers into the process of resolving conflict by taking responsibility for the problems of crop pests, then any large-scale solution that involves continuous funding from outside the community will eventually fail. We suggest that the more responsibility farmers have for crop protection, the more successful deterrence will be. The role of external agencies and wildlife managers is, therefore, to work with farmers to develop a range of management solutions for repelling elephants. This strategy appears to have a greater chance of success than one-off technical solutions or centralized PAC units because each conflict situation has its own local characteristics. It is unlikely that the problem of crop loss will ever be eliminated entirely, but integrated management solutions such as those described in this paper may go some way towards mitigating the impact of elephants on rural farmers.

\section{Acknowledgements}

The authors wish to thank two anonymous reviewers and Lucy Welford for their comments on earlier drafts of this manuscript. The Wildlife Conservation Society, US Fish and Wildlife Service, and the National Geographic Society fund the research of the Mid Zambezi Elephant Project.

\section{References}

AfESG (2000) Review of Compensation Schemes for Agricultural and Other Damage Caused by Elephants. Human-Elephant Conflict Working Group, http:/www.iucn.org/themes/ssc/ sgs/afesg/hectf [accessed 21 June 2001].

Barnes, R.F.W., Azika, S. \& Asamoah-Boateng, B. (1995) Timber, cocoa, and crop-raiding elephants: a preliminary study from southern Ghana, Pachyderm, 19, 33-38.

Bell, R.H.V. (1984) The man-animal interface: an assessment of crop damage and wildlife control. In Conservation and Wildife Management in Africa (eds R.H.V. Bell \& T. Mcshane-Caluzi), pp.25-37. US Peace Corps, Lilongwe, Malawi.

Gorman, M.L. (1986) The secretion of the temporal gland of the African elephant, Loxodonta africana, as an elephant repellent. Journal of Tropical Ecology, 2, 187-190.

Hill, C.M. (1998) Conflicting attitudes towards elephants around the Budongo Forest Reserve, Uganda. Environmental Conservation, 25, 244-250.

Hill, C.M., Osborn, F.V. \& Plumptre, A.J. (2000) Human-Wildlife Conflict: Identifying the problem and possible solutions. Albertine Rift Technical Reports Series, Vol. 1, Wildlife Conservation Society, Kampala, Uganda.

Hoare, R.E. (1995) Options for the control of elephants in conflict with people. Pachyderm, 19, 54-63.

Hoare, R.E. (2000) Projects of the Human Elephant Conflict Taskforce, results and recommendations. Pachyderm, 28, 73-78.

Hoare, R.E. (2001) Management implications of new research on problem elephants. Pachyderm, 30, 44-48.

Kangwana, K. (1993) Elephant and Maasi: conflict and conservation in Amboseli, Kenya. PhD thesis, University of Cambridge, Cambridge, UK.

Lahm, S. (1996) A nation-wide survey of crop raiding by elephants and other species in Gabon. Pachyderm, 21, 69-77.

Langbauer, W., Payne, K.B., Chairf, C., Rapaport, L. \& Osborn, F. (1991) African elephants respond to distant playbacks of low frequency conspecific calls. Journal of Experimental Biology, 157, 35-46.

Languy, M. (1996) Suivi et attenuation de l'impact des elephants et autres mammiferes sauvages sur l'agriculture au Gabon. Unpublished Report, WWF Gabon, Libreville, Gabon. 
MZEP (2001) Community-based PAC methods in Zimbabwe; Progress report to the Wildlife Conservation Society, Bronx, New York

O'Connell-Rodwell, C.E., Rodwell, T., Rice, M. \& Hart, L.A. (2000) Living with the modern conservation paradigm: can agricultural communities co-exist with Elephants? A fiveyear Case Study in East Caprivi, Namibia. Biological Conservation, 93, 381-391.

Osborn, F.V. (1998) The ecology of crop-raiding elephants in Zimbabwe, $\mathrm{PhD}$ thesis, University of Cambridge, Cambridge, UK.

Osborn, F.V. \& Parker, G.E. (2002) Community-based methods to reduce crop loss to elephants: experiments in the communal lands of Zimbabwe. Pachyderm, 33, 22-31.

Osborn, F.V. \& Welford, L.A. (1997) Living with Elephants: A Manual for Wildlife Managers in the Sadc Region. Southern African Development Community/Natural Resources Management Programme, Liloagwe, Malawi.

Osborn, F.V. \& Rasmussen, L.E.L. (1995) Evidence for the effectiveness of an oleo-resin capsicum against wild elephants in Zimbabwe. Pachyderm, 20, 15-22.

Perrin, T.E., Rasmussen, L.E.L. \& Gunawardena, R. (1996) A method for collection, long-term storage and bioassay of labile volatile chemosignals. Journal of Chemical Ecology, 21, 207-221.

Seidensticker, J. (1984) Managing Elephant Depredation in Agricultural and Forestry Projects. The World Bank, Washington, D.C., USA.

Taylor, R.D. (1982) Buffer zones: Resolving conflict between human and wildlife interests in the Sebungwe region. Zimbabwe Agricultural Journal, 79, 179-184.
Taylor, R.D. (1999) A Review of Problem Elephant Policies and Management Options in Southern Africa. Human-Elephant Conflict Task Force, IUCN African Elephant Specialist Group, Nairobi, Kenya.

Thouless, C.R. (1994) Conflict Between Humans and Elephants in Sri Lanka. Unpublished Report, Global Environment Facility, Environment and Development Group, Oxford, UK.

Thouless, C.R. \& Sakwa, J. (1995) Shocking elephants: fences and crop raiders in Laikipia District, Kenya. Biological Conservation, 72, 99-107.

Van der Wittenboren (1999) An evaluation of CAMPFIRE in Muzarabani District, Zimbabwe. BSc thesis, University of Rotterdam, Holland.

Whyte, I. (1993) The movement patterns of elephant in the Kruger National park in response to culling and environmental stimuli. Pachyderm, 16, 72-80.

Wunder, M.B. (1996) Of elephants and men: crop destruction in two CAMPFIRE communities in the Zambezi Valley, Zimbabwe. DPhil. Thesis, University of Michigan, Michigan, USA.

\section{Biographical sketches}

Ferrel Osborn and Guy Parker study elephant-human conflict in the Zambezi Valley of Zimbabwe. Their current research includes the use of pest resistant cash crops and improving the food security of communal farmers living with elephants. They also continue to work on strategies to enable farmers to defend their fields using locally available materials. 